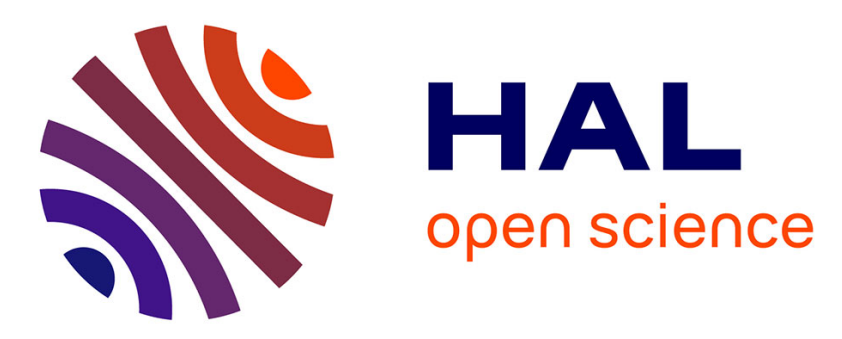

\title{
Hepatic stellate cells stimulate HCC cell migration via Laminin-5 production
}

\author{
Angela Santamato, Emilia Fransvea, Francesco Dituri, Alessandra Caligiuri, \\ Michele Quaranta, Tomoaki Niimi, Massimo Pinzani, Salvatore Antonaci, \\ Gianluigi Giannelli
}

\section{To cite this version:}

Angela Santamato, Emilia Fransvea, Francesco Dituri, Alessandra Caligiuri, Michele Quaranta, et al.. Hepatic stellate cells stimulate HCC cell migration via Laminin-5 production. Clinical Science, 2011, 121 (4), pp.159-168. 10.1042/CS20110002 . hal-00692133

\section{HAL Id: hal-00692133 https://hal.science/hal-00692133}

Submitted on 28 Apr 2012

HAL is a multi-disciplinary open access archive for the deposit and dissemination of scientific research documents, whether they are published or not. The documents may come from teaching and research institutions in France or abroad, or from public or private research centers.
L'archive ouverte pluridisciplinaire HAL, est destinée au dépôt et à la diffusion de documents scientifiques de niveau recherche, publiés ou non, émanant des établissements d'enseignement et de recherche français ou étrangers, des laboratoires publics ou privés. 


\title{
Hepatic stellate cells stimulate HCC cell migration via Laminin-5 production
}

\begin{abstract}
Angela Santamato ${ }^{1}$, Emilia Fransvea ${ }^{1}$, Francesco Dituri $^{1}$, Alessandra Caligiuri ${ }^{2}$, Michele Quaranta ${ }^{3}$, Tomoaki Niimi ${ }^{4}$, Massimo Pinzani ${ }^{2}$, Salvatore Antonaci ${ }^{1}$, Gianluigi Giannelli ${ }^{1}$
\end{abstract}

${ }^{1}$ Department of Internal Medicine, Immunology and Infectious Diseases, Section of Internal Medicine; University of Bari Medical School, Bari, Italy; ${ }^{2}$ Department of Internal Medicine, University of Florence Medical School, Florence, Italy; ${ }^{3}$ Department of Experimental Oncology, Laboratory of Analyses; National Cancer Institute, Bari, Italy; ${ }^{4}$ Laboratory of Industrial Biosciences, Department of Bioengineering Sciences, Nagoya University, Japan.

Keywords: liver fibrosis, extra-cellular matrix proteins, tumor-host interaction, laminin, cell motility.

Running title: HSCs stimulate HCC migration

Correspondence should be addressed to: Gianluigi Giannelli, Dipartimento di Clinica Medica, Immunologia e Malattie Infettive, Sezione di Medicina Interna, Policlinico, piazza G. Cesare 11, 70124 Bari, Italy. Tel. ++ 39 (080) 5478-127; Fax: ++ 39 (080) 5478-126; e-mail: g.giannelli@intmed.uniba.it.

\begin{abstract}
Activated Hepatic stellate cells (HSCs) are the main source of extracellular matrix proteins present in cirrhotic liver on which hepatocellular carcinoma (HCC) commonly develops. HCC cells behave differently according differences in the surrounding microenvironment. In this study we investigate a mechanism whereby HSCs modulate the migratory activity of HCC cells. We used primary cultures of human HSCs to investigate their effect on Hep3B, Alexander, HLE and HLF HCC cells. The expression of Laminin-5 (Ln-5) was documented at transcript and protein levels both in vitro and in vivo.HCC cells strongly adhere, migrate and spread in the presence of HSCs conditioned media and of co-culture. HSCs produce and secrete Ln-5 in the conditioned medium. The electrophoretic pattern of secreted Ln-5 is consistent with that of a migratory substrate, showing the presence of the $\gamma 2 \mathrm{x}$ fragment. Blocking antibodies against Ln-5 inhibit HCC migration in the presence of HSCs conditioned media. HCC cells migrate very poorly in the presence of Ln-5 immuno-depleted HSCs conditioned medium. HCC migration in the presence of HSCs is dependent on the MEK/Erk but not the PI3K/Akt pathway. HSCs conditioned medium, as well as Ln-5, activates the MEK/Erk but not the PI3K/Akt pathway. In human HCC tissues, Ln-5 is mainly distributed along a-SMA positive cells, whereas in peritumoral tissues Ln-5 is absent. HSCs stimulate HCC migration via the production and secretion of Ln-5.
\end{abstract}




\section{Introduction}

In western industrialized Countries, hepatocellular carcinoma (HCC) commonly develops on cirrhotic livers, so liver cirrhosis is considered a premalignant disease and screening programs are strongly recommended [1]. HCC cells grow embedded in fibrillar extracellular matrix proteins (ECM) as a consequence of the underlying cirrhosis. The ECM proteins are engaged by integrins, a family of heterodimeric transmembrane receptors that deliver intracellular signals ensuring cellular homeostasis and biological function [2]. For this reason, the cross-talk between HCC cells and the surrounding microenvironment is believed to play a pivotal role in modulating the biological behavior of the tumor, likely affecting a different clinical outcome.

During chronic liver damage, HSCs become activated, and assume a myofibroblast-like phenotype. As a consequence they proliferate, migrate towards the area of ongoing tissue remodelling and secrete the ECM proteins [3]. It is not known whether different qualitative and quantitative compositions of ECM proteins display a different effect in HCC, but we have previously reported a role for Laminin-5 (Ln5), recently renamed Ln-332, in patients with HCC [4]. Ln-5 is a member of the Ln family, composed of three different chains, $\alpha 3, \beta 3$, and $\gamma 2$, assembled in a coiled structure linked by disulfide bounds [5]. Ln-5 has been widely reported to be involved in a more malignant phenotype of several different cancers including HCC [6]. In particular, we showed that the presence of the $\gamma 2$ chain was correlated with a worse prognosis and shorter survival in patients with HCC [4]. Ln-5 promotes static adhesion but after proteolytic remodelling of the $\gamma 2$ chain with the generation of a $\gamma 2 x$ fragment, it promotes strong migration $[7,8]$.

Aim of this study is to investigate the role of HSC cells in modulating the biological activity of HCC cells, with a particular focus on the role of $\mathrm{Ln}-5$ as promoter of a motile phenotype in HCC cells .

\section{MATERIALS AND METHODS}

\section{Cell Culture and Reagent}

The human HCC cell lines Hep3B, Alexander HLE and HLF, were cultured as previously reported [9]. Hepatic Stellate Cell (HSCs) were isolated from healthy donors undergoing surgery, characterized and maintained in culture as previously described [10,11]. Briefly,

HSCs were isolated from wedge sections of normal human liver tissue unsuitable for transplantation, by collagenase-pronase digestion and centrifugation on stractan gradients. Procedures used for cell isolation and characterization have been extensively described elsewhere. Cells were cultured in IMDM supplemented with $20 \% \mathrm{FBS}$, subcultured when confluent at a 1:3 split ratio, and used for passages 3 to 8. Mouse monoclonal antibody against the $\mathrm{NH}_{2}$-terminal region of the human laminin5 $\alpha 3$ chain (LS $\alpha$ c1, used at 1:400) was kindly provided by Prof. K. Miyazaki (Bioscience and Technology, International Graduate School of Arts and Sciences, Yokohama, Japan). Mouse monoclonal antibody against the human Ln-5 $\beta 3$ chain 
and Collagen I were purchased from Biosciences Pharmingen (San Jose, CA). Rabbit polyclonal antibody against Laminin-5 $\gamma 2$ chain (used at 1:100) was a kind gift from Prof. Sirla Sapo (Dipartment of Biochemistry, University of Oulu, Finland).

Blocking antibody against the human Ln-5 $\alpha 3$ chain, BM165, was a kind gift from Prof. P. Rousselle of the Department of Dermatology, Stanford Medical Center, USA. Gelatin was purchased from Merck (Milan, Italy). Fibronectin (FN) was purchased from Calbiochem (San Diego, CA). Rabbit polyclonal antibody Akt total, rabbit monoclonal antibody Phospho-Akt (Ser473), rabbit monoclonal antibody Erk and mouse monoclonal antibody Phospho-Erk (Thr202/Tyr204) were purchased from Cell Signaling Tecnology (Massachusetts, USA). LY294002, a cell permeable, specific inhibitor of the Akt pathway, in particular of phosphatidylinositol 3- Kinase (PI3K) and PD98059, a cell permeable inhibitor of the Erk pathway, in particular of MAP kinase kinase (MEK), were purchased from Calbiochem, Germany. Monoclonal antibody anti- $\alpha$ SMA (1A4) was purchased from Sigma Aldrich, Germany, antibody against E-cadherin was purchased from BD (Biosciences, San Jose, CA)

\section{Collection of HSC conditioned medium}

The HSCs conditioned medium (CM) was collected after culturing confluent cells for forty-eight hours in serum-free medium. At this point, the HSCs-CM was centrifuged and frozen at $-20^{\circ} \mathrm{C}$. A new aliquot was used for each experiment. To obtain Ln-5-depleted HSCS-CM, serum-free CM was incubated with the anti-Ln-5 antibody (ab14509, ABCAM, UK) overnight at $4^{\circ} \mathrm{C}$ under rotation. Then, beads conjugated with protein G (sc-2002 Santa Cruz Biotecnology, Heidelberg, Germany), which recognise the fragment $\mathrm{Fc}$ of antibody, were added for 1 hour at $4{ }^{\circ} \mathrm{C}$ under rotation. Finally, the $\mathrm{CM}$ was centrifuged for 15 minutes at $4300 \mathrm{rpm}$ and the supernatant collected.

\section{Adhesion, Migration and Scattering Assays}

Adhesion, migration and scattering assays were performed as previously described [9]. Briefly, $30 \times 10^{3}$ and $75 \times 10^{3}$ cells were used for migration and scattering assays, respectively. Coatings for adhesion and migration were prepared with FN used at $10 \mu \mathrm{g} / \mathrm{ml}$ as well as Coll I, with gelatin at $0.2 \%$ diluted in PBS for 2 hours at $37^{\circ} \mathrm{C}$. As negative control, wells were coated with blocking solution only. In migration assays, HSCs-medium was used as control. In some experiments, the blocking antibody against Ln-5, BM165, at 50 and $100 \mu \mathrm{g} / \mathrm{ml}$, was added, while an $\mathrm{IgG}$ at the maximum concentration was used as control. Other experiments were performed using Ln-5 depleted HSCs-CM, and the same HSCs-CM treated with beads without the antibody as control. In adhesion assays, after 30 minutes cells were gently washed for 10 minutes, adherent cells were fixed with paraformaldehyde at 4\% in PBS (Phosphate Buffered Saline) for 20 minutes, stained with crystal violet for 30 minutes and abundantly washed to remove the dye. The next day, cells were solubilised with SDS $1 \%$ and the optical absorbance was read at $570 \mathrm{nM}$ on an ELISA reader. 
In scattering experiments, BM165 was added at $100 \mu \mathrm{g} / \mathrm{ml}$ and $\mathrm{Ln}-5$ at $1 \mu \mathrm{g} / \mathrm{ml}$. All the functional assays were repeated at least three times for all the HCC cell lines used (HLE, HLF, Alexander and Hep3B). Results were consistent and similar for all the cell lines, therefore to avoid unnecessary repetition we have shown only representative experiments on few cell lines. Cell scattering was quantified by counting the number of islets in ten randomly chosen microscopic fields for each condition. The mean and standard deviation of three independent experiments are represented as histograms.

\section{Western Blot Analysis}

Cell lysates were prepared directly in the cell extraction buffer Biosource International Inc. (Milan, Italy), supplemented with a protease inhibitor cocktail Sigma (Milan, Italy), as previously described [12]. Conditioned media were concentrated by centricon Millipore (Billerica, MA). Ail the samples were normalized for protein concentration, measured by the bicinchoninic acid method (Pierce Chemical Co., Rockford, IL).

\section{Real-Time RT-PCR Analysis}

Real-Time PCR analysis was performed according to the manufacturer's instructions (SYBR Green PCR Master Mix, Applied Biosystems, Austin,TX) using the iCycler thermal 7300 Real-Time PCR System, Applied Biosystems. Ln-5 $\alpha 3$, Ln$5 \beta 3$, Ln-5 $\gamma 2$ and E-cadherin, gene expression was measured and compared with GAPDH expression. The sequences and product size of the oligonucleotides were: GAPDH, 5'-CCACATCGCTCAGACACCAT-3' ${ }^{\prime}$ and 'GCGCCCAATACGACCAAAT-3'; ${ }^{\prime}$ Ln-5 $\quad \alpha 3, \quad 5^{\prime}-$ AAGCAAGGAGAAATGCAATGATG-3' and 5'-CAACCAAGCGCCCCTTTT-3'; Ln-5 $\quad 33, \quad 5$ '-GCAGGTCCACGATGTCTGTGT-3' and 5'CAGTCGCACCTTTGGCATT-3'; Ln-5 $\quad \gamma 2, \quad 5$ 'AAAGGTTCTCTTAGTGCTCGATGTG-3' and 5'-CGCATCCGTGAGCATGTG3'; E-Cadherin, 5'-TCA GCC GCT TTC AGA TTT TCA-3' and 5'-ATG AGT GTC CCC CGG TAT CTT-3'.

\section{Immunofluorescence staining}

HSCs were plated on coverslips (12 mm pore size) in 24-well with IMDM added with 10\% FBS. After 2-3 days the HSCs were fixed with paraformaldehyde at $4 \%$ in PBS, for 5 minutes. The aspecific sites were blocked for 30 minutes with a blocking solution, composed of $2 \%$ BSA and $0.01 \%$ Triton $\mathrm{x}-100$ in PBS. Then the HSCs were incubated for 1 hour with primary antibodies: monoclonal antibodies anti$\alpha$-SMA, anti- $\alpha 3$ chain of Ln- 5 , anti- $\beta 3$ chain of Ln- 5 and the polyclonal antibody anti- $\gamma 2$ chain of Ln-5, diluted in blocking solution. After three washes in PBS, the cells were incubated with secondary antibodies conjugated to fluorophores and the Dapi (Sigma) to stain the nuclei. Then the coverslips were mounted with an antireflection solution (Biorad, Hercules, CA, USA) and observed by fluorescence microscopy. The immunofluorescence was also analyzed on tumoral and peritumoral 
tissues of HCC patients. The tissues were fixed with acetone/chloroform for 20 minutes. The aspecific sites were blocked for 30 minutes with a blocking solution, composed of 10\% Goat Serum (Sigma Aldrich, Germany) in RPMI. Then the tissues were incubated for 1 hour with the monoclonal antibody anti- $\alpha$-SMA and the polyclonal antibody anti- $\gamma 2$ chain of Ln-5, both diluted in the blocking solution. After three washes in TBS (Tris Buffered Saline), the tissues were incubated with secondary antibodies conjugated to fluorophores. Then the coverslips were mounted with an anti-reflection solution and observed by fluorescence microscopy. The microscopy images were acquired by camera (Digital Camera DXM 1200 Nikon, Tokyo, Japan), using LUCIA- G software (Laboratory Imaging s.r.o, Prague, Czech Republic).

\section{Human tissues}

Tumoral and paired peritumoral tissues were collected from ten $\mathrm{HCC}$ patients undergoing surgery (age range: 62-81 years). All the specimens, were fixed in 3.7\% formaldehyde and processed for routine histology, while a part of the specimen was immediately snap-frozen in liquid nitrogen and stored at $-80 \mathrm{C}^{\circ}$ until use. All patients also had underlying cirrhosis, $8 / 10$ had $\mathrm{HCV}$ and the remaining $2 \mathrm{HBV}$. The study was performed in accordance with the Helsinki declaration and informed written consent was obtained from all patients before surgery in accordance with the priorgranted ethics committee approval.

\section{Results}

All the experiments were replicated at least three times. As regards HSCs, each experiment was repeated in four different cell preparations, each obtained from a different donor, and results were consistent in all the different HSCs preparations. All the experiments were conducted using HSCs at low passages (from three to eight). To investigate the effect of HSCs on HCC cell behavior we firstly allowed four different HCC cell lines, HLF, HLE, Alexander and Hep3B, to adhere on different ECM proteins such as Fn, Coll I and gelatine in the presence of HSC-medium (HSC-M) and of serum-free HSC-conditioned medium (CM). Overall, HCC cells adhere with a different efficiency on Fn and Coll I in the presence of HSC-M, but when plated in the presence of HSC-CM, cells adhere significantly $(\mathrm{p}<0.005)$ more strongly on all the tested substrates. This finding was more evident using gelatine as a substrate since all the cell lines were poorly adherent, but became strongly adherent $(\mathrm{p}<0.001)$ in the presence of HSC-CM, Fig.1A.

To further investigate the effect of HSCs on HCC cells, we challenged the HCC cells to migrate on FN, Coll I and gelatine in the presence of HSC-M and HSC$\mathrm{CM}$. HCC cells were more migratory on all the substrates in the presence of HSC$\mathrm{CM}$ as compared to HSC-M $(\mathrm{p}<0.001)$. An even stronger migration was observed when HCC cells were seeded in the upper part of the chamber and HSCs in the bottom part of the chamber in a fresh serum-free medium. This effect was not evident for HLE and HLF cells, that constitutively exert a strong migration on FN even in the presence of HSC-M, used as positive control, Fig.1B-C. This suggests that HSCs are 
able to stimulate HCC cell adhesion and migration by secreting a chemoattractant factor in the conditioned medium.

On the contrary, HSC-CM did not exert any effect, as compared to HSC-M, on HCC proliferation measured by cell number counting and crystal violet staining over a time ranging up to nineteen hours (data not shown), suggesting a specific promigratory effect of the HSC-CM.

Because we have already observed the presence of Ln-5 in HCC tissues, Ln-5 supports cell migration and HSCs are the main source of ECM production, we tested the hypothesis that HSCs produce and secrete Ln-5. For this purpose, HSC cell lysate as well as HSC-CM were separated by western blotting and the membrane was blotted with antibodies directed against $\alpha 3, \beta 3$ and $\gamma 2$ chains. All the Ln-5 chains were present in both the lysate and the CM. The $\beta 3$ and $\gamma 2$ chains showed a different electrophoretic pattern in the two preparations, consistently with the extracellular processing. In particular, the $\gamma 2$ chain is almost cleaved into the $\gamma 2 \mathrm{x}$ fragment in the $\mathrm{CM}$ as we previously described to support migration activity [7], Fig.2A. The $\beta 3$ chain also appears cleaved in the $\mathrm{CM}$ but at the moment the biological significance of this processed chain ( $\left.\beta 3^{\prime}\right)$ is still unknown. The production of Ln-5 by HSC cells was confirmed by real-time PCR, that showed the presence of mRNA of all three Ln5 chains, Fig.2B. Finally, this finding was also proven by immunofluorescence. HSCs were stained with a monoclonal antibody directed against a-SMA and against the $\alpha 3$, $\beta 3$ chains and with a polyclonal antibody against the $\gamma 2$ chain of Ln-5, showing that HSCs produce Ln-5, Fig.2C. In conclusion, HSCs produce and secrete all parts of Ln5 in the conditioned medium.

To prove that the Ln-5 present in the HSC-CM promoted migration of HCC cells, we added a monoclonal functional antibody directed against Ln-5, BM165, to Alexander and Hep3B and challenged them to migrate on gelatine. HSC-CM induced migration was significantly $(p<0.01)$ inhibited, in a dose dependent manner, using the BM165 antibody whereas cells migrated efficiently in the presence of an IgG used as control, Fig.3A. To support this hypothesis, we studied the scattering activity of Ln5. HCC cells grow in island-like structures in the presence of control HSCs-medium, while in the presence of serum-free HSCs-CM, cells lose cell-cell contact, change their morphology, assuming a motile phenotype, and finally scatter. In the presence of BM165 blocking antibody directed against Ln-5 this effect is reversed. In controls, purified hLn-5 promotes scattering of the HCC cells, this activity also being reversed by BM165. To quantify the scattering activity, we measured the number of islets in each microscopic field. As reported in Fig.3B, the number of HLF and Hep3B islets was significantly reduced $(p<0.01)$ in the presence of HSC-CM and Ln-5 as compared to control, but the addition of BM165 to the HSC-CM and to Ln-5 inhibited this effect, and the number of islets was significantly $(\mathrm{p}<0.01)$ increased. To further characterize the scattering activity we investigated the expression of Ecadherin by means of immunofluorescence and real-time PCR. As shown in Fig.3C, HLF express E-cadherin on the cellular surface at cell-cell contact in the presence of HSC-M, whereas in the presence of HSC-CM and Ln-5 the expression of E-cadherin 
was strongly reduced as a consequence of the scattering. However, in the presence of BM165, added to the HSC-CM or to Ln-5, E-cadherin was detectable to the same extent as in the controls. E-cadherin RNA levels were significantly down-regulated by HSC-CM $(p<0.01)$ and Ln-5 $(p<0.05)$, but this effect was inhibited in the presence of BM165, Fig.3C. In conclusion, the migration and scattering activity promoted by the HSCs-CM is inhibited by the blocking antibody directed against Ln-5.

To further demonstrate this mechanism we used a different experimental approach, preparing HSCs-CM immuno-depleted of Ln-5 using beads coated with an anti-Ln-5 antibody. Alexander and Hep3B cells were allowed to migrate on gelatine in the presence of Ln-5 depleted HSCs-CM . Both cell lines showed a significantly reduced cell migration when in the presence of the Ln-depleted HSCs-CM as compared to HSCs-CM and to HSCs-CM treated with uncoated beads used as control, Fig.4A. To confirm the immunodepletion of Ln-5 we investigated the presence of Ln-5 by western blotting. A monoclonal antibody directed against $\beta 3$ revealed that Ln-5 was present in the HSCs-CM as well as in the -CM treated with uncoated beads, whereas it was strongly reduced in the immuno-depleted medium, Fig.4B. This further supports the hypothesis that $\mathrm{Ln}-5$, present in the HSCs-CM, support HCC cell migration.

To investigate the molecular pathways supporting this migratory activity, we added PD98059 and LY294002 (inhibitors of MEK/Erk and PI3K/Akt, respectively) to HLF, HLE, Hep3B and Alexander cells in a migration assay in the presence of HSC-CM or Ln-5. PD98059 strongly ( $p<0.001)$ reduced cell migration on gelatine stimulated by HSC-CM, whereas LY294002 did not affect migration. Consistently, migration on Ln-5 in the presence of HSC-M was also significantly $(\mathrm{p}<0.001)$ inhibited by PD98059 whereas LY294002 displayed only a marginal effect on Alexander and Hep3B and no effect on HLE and HLF, Fig. 5A. All the different cell lines treated with HSC-CM or Ln-5 were lysed, electrophoresed and the membranes probed with antibodies against p-Akt and p-Erk1/2. As shown in Fig.5B, p-Akt was strongly activated by HSC-CM but not by Ln-5, as compared to the control medium. On the contrary, p-Erk was activated by both HSC-CM and Ln-5 as compared to controls, although the effect of HSC-CM was more evident. These results suggest that the HSC-CM, similarly to Ln-5, induces migration via MEK/Erk.

Finally, we investigated the expression of Ln-5 in ten human $\mathrm{HCC}$ and paired peritumoral samples. As reported in Fig. 6, in HCC tissues Ln-5 is expressed near to $\alpha$-SMA positive cells, likely HSCs. In many cases, Ln-5 and $\alpha$-SMA staining are co-localized, suggesting that these cells produce Ln-5, thus confirming the in vitro data. In peritumoral tissue, the presence of Ln-5 is very weak or absent, while $\alpha$ SMA positive cells are still evident. These results were consistently observed in all the tissues examined, but with a patchy pattern among sections. 


\section{Discussion}

Our study demonstrates, for the first time, that HSCs promote migration of HCC cells through the production and secretion of Ln-5, thus activating the MEK/Erk pathway. We base this conclusion on the following data: 1) HSCs conditioned media stimulate migration of HCC cells; 2) HSCs produce and secrete the entire Ln-5 molecule in the conditioned medium; 3) blocking antibody against Ln-5 inhibits the scattering and migration of HCC cells triggered by the HSCs conditioned medium; 4) the migration of HCC cells is strongly reduced in the presence of Ln-5 immunodepleted HSCs conditioned medium; 5) HSC-CM and Ln-5 stimulate migration via the MEK/Erk pathway.

In vitro, HSCs have been shown to stimulate proliferation and migration of HCC cells, likely because of the plethora of proteins and growth factors secreted, leading to activation of the Erk pathway [13]. The novelty in this study is that we demonstrate that HSCs stimulate migration via the production of Ln-5. We also confirm that HSCs-CM activates Erk, but we additionally show that Ln-5 also activates Erk and that this migration is blocked by inhibiting Erk activation. On the other hand, we cannot rule out other possible mechanisms triggered by HSC cells. These data corroborate our previous observation that Ln-5 is differently expressed in metastatic and non metastatic HCC [4]. In addition, HSCs have been reported to play a role in the tumoral progression of $\mathrm{HCC}$, since their presence in the peritumoral tissue is associated with strong vascular invasion and with more aggressive overall pathological characteristics [14]. Nevertheless, how HSCs modulate HCC cell invasive phenotype is still unclear, although it is reasonable to suppose that more than one mechanism takes place. In this context, our study firstly shows that HSCs produce and secrete Ln-5. This laminin isoform has been demonstrated to support solid adhesion as well as migration and invasion [15]. These opposite functions depend on the different biochemical status of the molecule, since proteolytic remodeling of the $\gamma 2$ chain converts a stationary molecule to a motile one $[7,16]$. In our case, the presence of the proteolytic fragment $\gamma 2 x$ in the conditioned medium has a molecular weight consistent with what has previously been described $[7,8]$. These findings can be explained by the fact that HSCs produce and secrete abundant levels of matrix metalloproteinase- 2 and membrane-type 1 matrix metalloproteinase, as already reported [17]. Alternatively, Ln-5 could be cleaved as a consequence of the proteolytic imbalance between MMP-2 and the physiologic inhibitor TIMP-2 described in HCC tissues [18]. Therefore, the presence of the cleaved Ln-5 $\gamma 2$ chain could facilitate the motility and spread of HCC cells. Alternatively, HSCs could trigger the epithelial mesenchymal transition of HCC cells via the secretion of Ln-5, leading to a more aggressive and invasive phenotype of the cancer [19]. This conclusion is consistent with a previous report suggesting that domains G4-5 of Ln5 are tumorigenic, activating the MEK/Erk pathway in squamous cellular carcinoma, and representing a potential therapeutic target [20].

In conclusion, although several proteins and growth factors can stimulate $\mathrm{HCC}$ cell motility, we demonstrate here that Ln-5 contributes to such a cross/talk, and also underline the role of the tissue microenvironment in affecting the biological 
properties of HCC, likely inducing a different clinical outcome. This emphasizes the need for new therapies able to target different tissue microenvironment components.

\author{
Author contribution \\ Experimental procedures: AS, FD, AC \\ Design of the experiments: $\mathrm{EF}, \mathrm{GG}$ \\ Interpretation of the results: $\mathrm{EF}, \mathrm{GG}, \mathrm{SA}$, \\ Fundamental reagents: TM \\ Preparation of the manuscript: GG, MP, MQ, SA
}

\title{
Acknowledgments \\ We are grateful to Mary V. Pragnell, B.A. for language revision.
}

\section{Funding}

This work was supported by the Italian Ministry of Health grant to GG number 202230GNN_08 


\section{References}

1. El Serag, H.B., Rudolph, K.L.,El Serag, H.B., Rudolph, K.L.(2007) Hepatocellular carcinoma: epidemiology and molecular carcinogenesis. Gastroenterology 132, 2557-2576

2. Hynes, R.O.,Hynes, R.O.(1987) Integrins: a family of cell surface receptors. Cell 48, 549554

3. Pinzani, M., Macias-Barragan, J.,Pinzani, M., Macias-Barragan, J.(2010) Update on the pathophysiology of liver fibrosis. Expert. Rev. Gastroenterol. Hepatol. 4, 459-472

4. Giannelli, G., Fransvea, E., Bergamini, C., Marinosci, F., Antonaci, S.,Giannelli, G., Fransvea, E., Bergamini, C., Marinosci, F., Antonaci, S.(2003) Laminin-5 chains are expressed differentially in metastatic and nonmetastatic hepatocellular carcinoma. Clin. Cancer Res. 9, 3684-3691

5. Burgeson, R.E., Chiquet, M., Deutzmann, R., Ekblom, P., Engel, J., Kleinman, H., Martin, G.R., Meneguzzi, G., Paulsson, M., Sanes, J.,Burgeson, R.E., Chiquet, M., Deutzmann, R., Ekblom, P., Engel, J., Kleinman, H., Martin, G.R., Meneguzzi, G., Paulsson, M., Sanes, J.(1994) A new nomenclature for the laminins. Matrix Biol. 14, 209-211

6. Guess, C.M., Quaranta, V.,Guess, C.M., Quaranta, V.(2009) Defining the role of laminin332 in carcinoma. Matrix Biol. 28, 445-455

7. Giannelli, G., Falk-Marzillier, J., Schiraldi, O., Stetler-Stevenson, W.G., Quaranta, V.,Giannelli, G., Falk-Marzillier, J., Schiraldi, O., Stetler-Stevenson, W.G., Quaranta, V.(1997) Induction of cell migration by matrix metalloprotease-2 cleavage of laminin-5. Science 277, 225-228

8. Koshikawa, N., Giannelli, G., Cirulli, V., Miyazaki, K., Quaranta, V.,Koshikawa, N., Giannelli, G., Cirulli, V., Miyazaki, K., Quaranta, V.(2000) Role of cell surface metalloprotease MT1-MMP in epithelial cell migration over laminin-5. J. Cell Biol. 148, 615-624

9. Giannelli, G., Bergamini, C., Fransvea, E., Marinosci, F., Quaranta, V., Antonaci, S.,Giannelli, G., Bergamini, C., Fransvea, E., Marinosci, F., Quaranta, V., Antonaci, S.(2001) Human Hepatocellular Carcinoma (HCC) Cells Require Both alpha3beta1 Integrin and Matrix Metalloproteinases Activity for Migration and Invasion. Lab Invest 81, 613-627

10. Pinzani, M., Failli, P., Ruocco, C., Casini, A., Milani, S., Baldi, E., Giotti, A., Gentilini, P.,Pinzani, M., Failli, P., Ruocco, C., Casini, A., Milani, S., Baldi, E., Giotti, A., Gentilini, P.(1992) Fat-storing cells as liver-specific pericytes. Spatial dynamics of agonist-stimulated intracellular calcium transients. J. Clin. Invest 90, 642-646

11. Casini, A., Pinzani, M., Milani, S., Grappone, C., Galli, G., Jezequel, A.M., Schuppan, D., Rotella, C.M., Surrenti, C.,Casini, A., Pinzani, M., Milani, S., Grappone, C., Galli, G., Jezequel, A.M., Schuppan, D., Rotella, C.M., Surrenti, C.(1993) Regulation of extracellular matrix synthesis by transforming growth factor beta 1 in human fat-storing cells. Gastroenterology 105, 245-253

12. Bergamini, C., Sgarra, C., Trerotoli, P., Lupo, L., Azzariti, A., Antonaci, S., Giannelli, G.,Bergamini, C., Sgarra, C., Trerotoli, P., Lupo, L., Azzariti, A., Antonaci, S., Giannelli, 
G.(2007) Laminin-5 stimulates hepatocellular carcinoma growth through a different function of alpha6beta4 and alpha3beta1 integrins. Hepatology 46, 1801-1809

13. Amann, T., Bataille, F., Spruss, T., Muhlbauer, M., Gabele, E., Scholmerich, J., Kiefer, P., Bosserhoff, A.K., Hellerbrand, C.,Amann, T., Bataille, F., Spruss, T., Muhlbauer, M., Gabele, E., Scholmerich, J., Kiefer, P., Bosserhoff, A.K., Hellerbrand, C.(2009) Activated hepatic stellate cells promote tumorigenicity of hepatocellular carcinoma. Cancer Sci. 100, 646-653

14. Ju, M.J., Qiu, S.J., Fan, J., Xiao, Y.S., Gao, Q., Zhou, J., Li, Y.W., Tang, Z.Y.Ju, M.J., Qiu, S.J., Fan, J., Xiao, Y.S., Gao, Q., Zhou, J., Li, Y.W., Tang, Z.Y.(2009) Peritumoral activated hepatic stellate cells predict poor clinical outcome in hepatocellular carcinoma after curative resection. Am. J. Clin. Pathol. 131, 498-510

15. Giannelli, G., Antonaci, S.,Giannelli, G., Antonaci, S.(2001) Biological and clinical relevance of Laminin-5 in cancer. Clin. Exp. Metastasis

16. Salo, S., Haakana, H., Kontusaari, S., Hujanen, E., Kallunki, T., Tryggvason, K.,Salo, S., Haakana, H., Kontusaari, S., Hujanen, E., Kallunki, T., Tryggyason, K.(1999) Laminin-5 promotes adhesion and migration of epithelial cells: identification of a migration-related element in the gamma2 chain gene (LAMC2) with activity in transgenic mice. Matrix Biol. 18, 197-210

17. Theret, N., Musso, O., Turlin, B., Lotrian, D., Bioulac-Sage, P., Campion, J.P., Boudjema, K., Clement, B.,Theret, N., Musso, O., Turlin, B., Lotrian, D., Bioulac-Sage, P., Campion, J.P., Boudjema, K., Clement, B.(2001) Increased extracellular matrix remodeling is associated with tumor progression in human hepatocellular carcinomas. Hepatology 34, 8288

18. Giannelli, G., Bergamini, C., Marinosci, F., Fransvea, E., Quaranta, M., Lupo, L., Schiraldi, O., Antonaci, S.,Giannelli, G., Bergamini, C., Marinosci, F., Fransvea, E., Quaranta, M., Lupo, L., Schiraldi, O., Antonaci, S.(2002) Clinical role of MMP-2/TIMP-2 imbalance in hepatocellular carcinoma. Int. J. Cancer 97, 425-431

19. Giannelli, G., Bergamini, C., Fransvea, E., Sgarra, C., Antonaci, S., Giannelli, G., Bergamini, C., Fransvea, E., Sgarra, C., Antonaci, S.(2005) Laminin-5 with transforming growth factor-beta1 induces epithelial to mesenchymal transition in hepatocellular carcinoma. Gastroenterology 129, 1375-1383

20. Tran, M., Rousselle, P., Nokelainen, P., Tallapragada, S., Nguyen, N.T., Fincher, E.F., Marinkovich, M.P.,Tran, M., Rousselle, P., Nokelainen, P., Tallapragada, S., Nguyen, N.T., Fincher, E.F., Marinkovich, M.P.(2008) Targeting a tumor-specific laminin domain critical for human carcinogenesis. Cancer Res. 68, 2885-2894 


\section{Figure legends}

Fig. 1. HSCs enhance HCC cell adhesion and migration. HLE, HLF, Alexander and Hep3B were plated in a ninety-six well plate coated with FN, Coll I and gelatine for thirty minutes. All the HCC cell lines adhere more efficiently when plated in the presence of HSC-CM as compared to HSC-M. Graphs refer to one experiment, and bars indicate the mean and standard deviation of each condition repeated in five wells, panel A. In a migration assay, HSCs were cultured at the bottom of the plastic well until confluence. Medium was removed and fresh serum-free medium added at the beginning of the experiment. HCC cell lines were seeded in the upper part of a modified Boyden chamber coated at the bottom part with FN, as positive control, Coll IV and gelatine. All the HCC cell lines migrated more efficiently in the coculture experiments as compared to the HSC-CM, panel B, upper part. In the bottom part of panel B, it can be seen that HSC-CM stimulated migration more efficiently than HSC-M on the same substrates. Each graph refers to one experiment and bars indicate the mean and standard deviation of four microscopic fields randomly chosen for each condition run in duplicate. In panel $\mathrm{C}$, microscopic pictures of migrated Alexander cells stained with toluidine blue, representative of the experiment described in panel B, are shown. Mag X 200.

Fig. 2. HSCs produce and secrete Ln-5. Western blot analysis of HSC lysates and conditioned media of membranes probed with antibodies against the $\alpha 3, \beta 3$ and $\gamma 2$ chains of Ln-5. In the conditioned medium $\beta 3$ and $\gamma 2$ appear as in the processed forms, panel A. mRNA expression of each chain quantified by real-time PCR, panel B. Immunofluorescence staining of Ln-5 using a polyclonal antibody against the $\gamma 2$ chain and a monoclonal against $\alpha$-SMA. Merged images confirm that HSCs produce Ln-5. In the bottom panel, monoclonal antibodies used to stain $\alpha 3, \beta 3$ and $\alpha$-SMA.

Fig. 3. Neutralizing antibody against Ln-5 inhibits HSC-CM stimulated motility. BM165, a neutralizing antibody against the $\beta 3$ chain of Ln-5, inhibits Alexander and Hep3B cell migration stimulated by HSC-CM in a dose-dependent manner, while no effect was displayed with IgG used as control, panel A. HLF and Hep3B cells grow in island-like structures. However, in the presence of HSC-CM or Ln-5 this structure is disassembled, cells change their morphology, acquiring a motile phenotype that leads to a scattering effect. The scattering effect was completely reversed by the presence of BM165 antibody, as shown by the quantification of Alexander and Hep3B cell scattering by counting the number of islets in each microscopic field, panel B. Immunofluorescence of E-cadherin on HLF cells in the same conditions as previously described. E-cadherin expression is detectable on the cell surface at cellcell contact in control conditions, but is decreased in the presence of HSC-CM and Ln-5. This effect was reversed by the BM165 antibody. E-cadherin RNA levels were investigated by mean of real-time PCR under the same experimental condition as previously described.

Fig. 4. Immunodepletion of Ln-5 inhibits HSC-CM stimulated migration. HSCCM was immunodepleted of Ln-5 with beads coated with anti-Ln-5 antibody. Alexander and Hep3B migration was strongly reduced in the presence of the 
immunodepleted HSC-CM as compared to migration in the presence of the control HSC-CM, panel A. Western blot analysis of untreated HSC-CM, or treated with uncoated beads or with beads coated with anti-Ln-5 antibody, and probed with the anti- $\beta 3$ and anti- $\gamma 2$ chain, to show the efficiency of the immunodepletion, panel B.

Fig. 5. HSC-CM and Ln-5 induce migration via p-Erk activation. Migration of HCC cells in the presence of inhibitors of the MEK/Erk (PD98059) and PI3K/Akt (LY294002) pathways. PD98052 blocks migration of all the HCC cell lines in the presence of HSC-CM and Ln-5, whereas PD98059 reduces migration on Alexander and Hep3B cells only, panel A. Western blotting analysis of HLE, HLF, Alexander and Hep3B cell lysate stimulated with HSC-CM and Ln-5. HSC-CM phosphorylates Akt and p-Erk, whereas Ln-5 phosphorylates only Erk.

Fig.6. Expression of Ln-5 in human tissues. In HCC tissues, Ln-5 (red) is abundantly expressed in the extra-cellular space, near to $\alpha$-SMA positive cells (green). In some cases, Ln- 5 is present inside the $\alpha$-SMA positive cells, so that a colocalization (yellow) is evident. In paired peritumoral tissues, $\alpha$-SMA positive cells are still present, while Ln-5 staining is absent. 
A

Figure 1
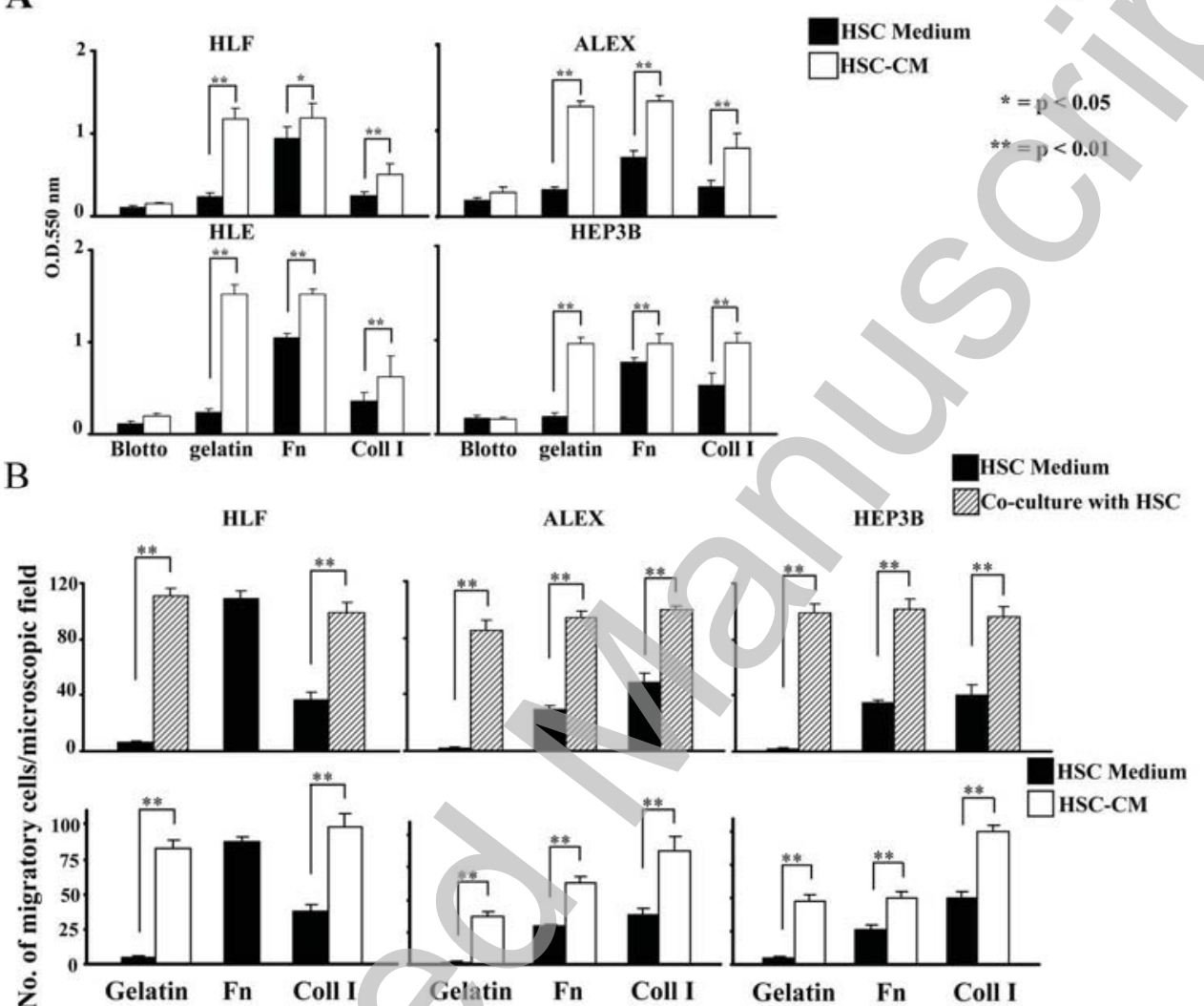

C

ALEX

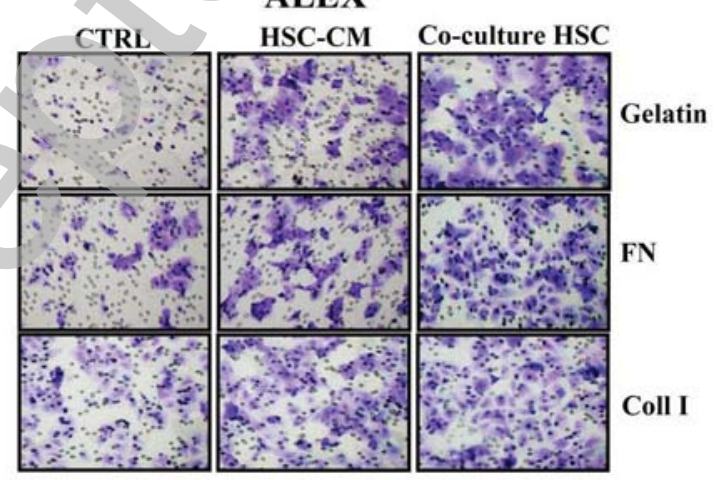

Licenced copy. Copying is not permitted, except with prior permission and as allowed by law. 
A

Figure 2

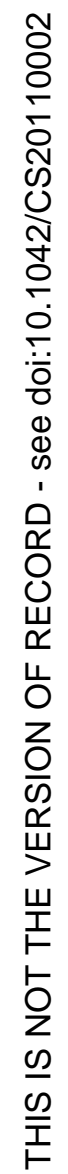

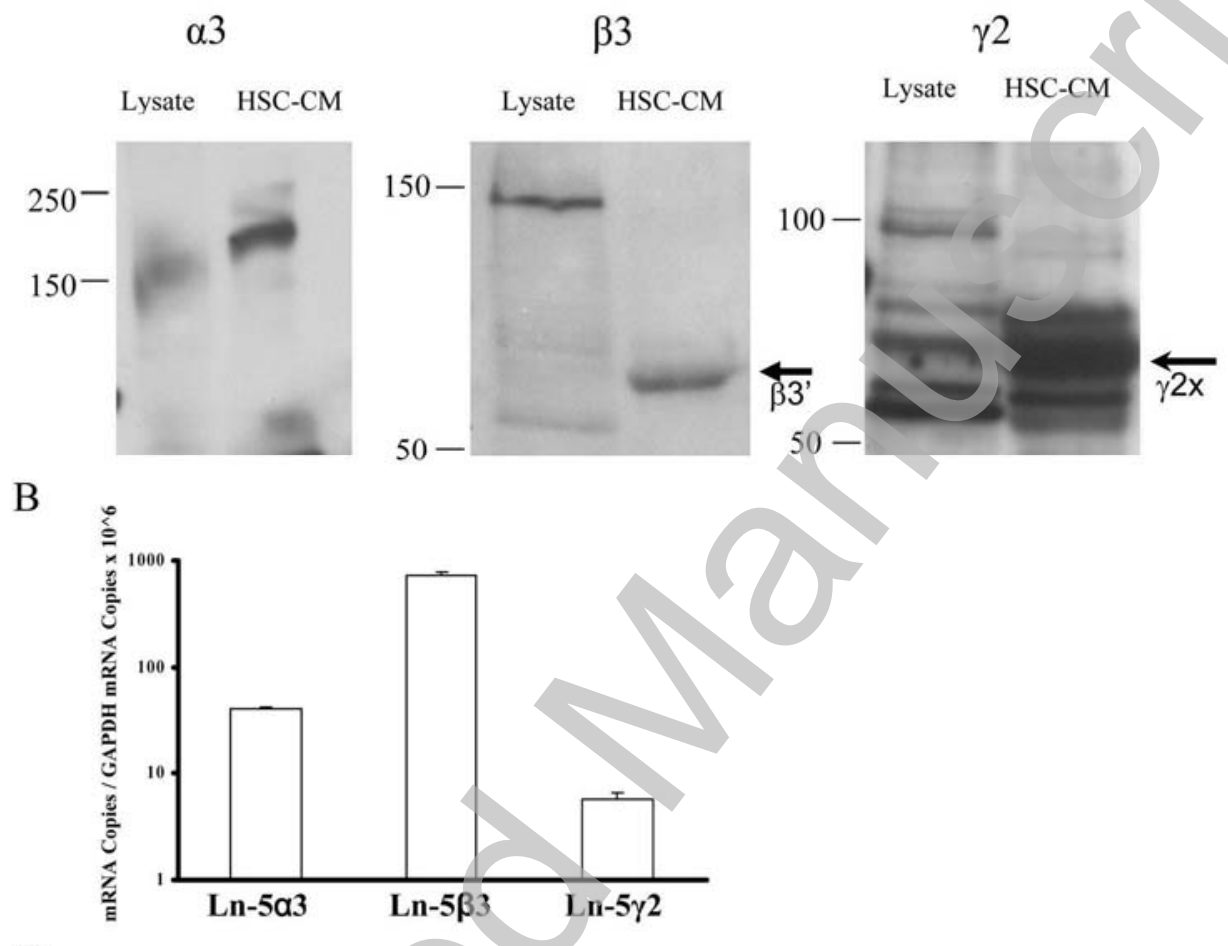

C
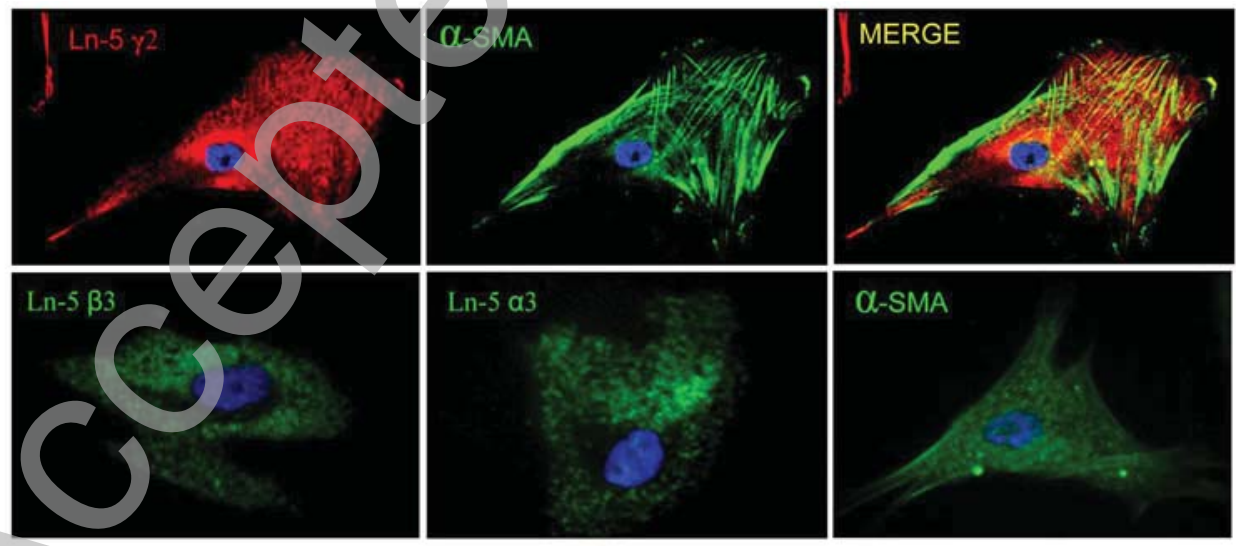

$\alpha$-SMA

Licenced copy. Copying is not permitted, except with prior permission and as allowed by law.

(C) 2011 The Authors Journal compilation (C) 2011 Portland Press Limited 
A
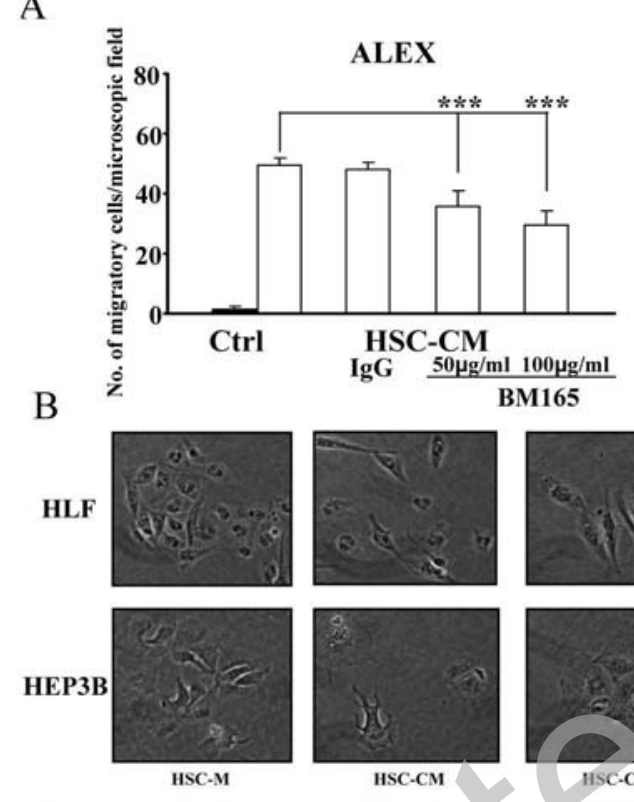

C
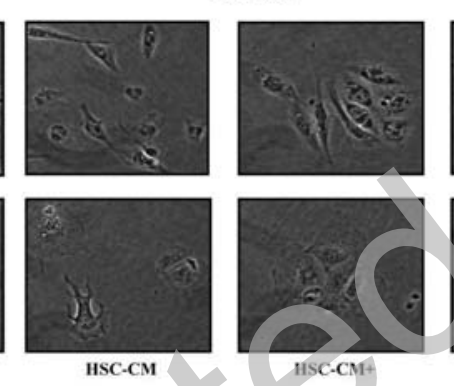

HSC.CMA

E-Cadherin

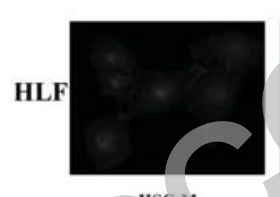

HSC.M

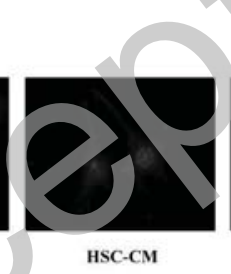

HSC-CM

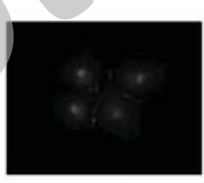

HSC.CM+
BM165 $1100 \mathrm{\mu g} / \mathrm{ml} /$

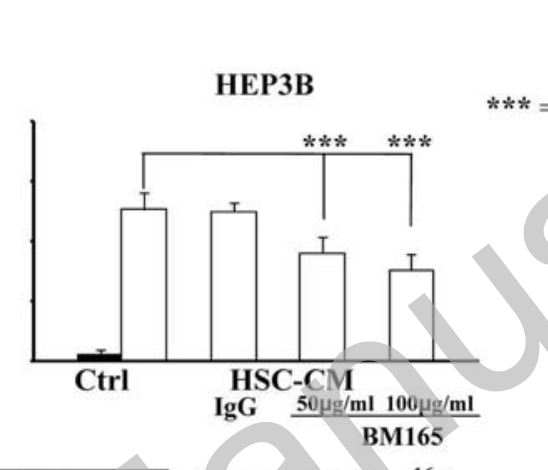

Figure 3
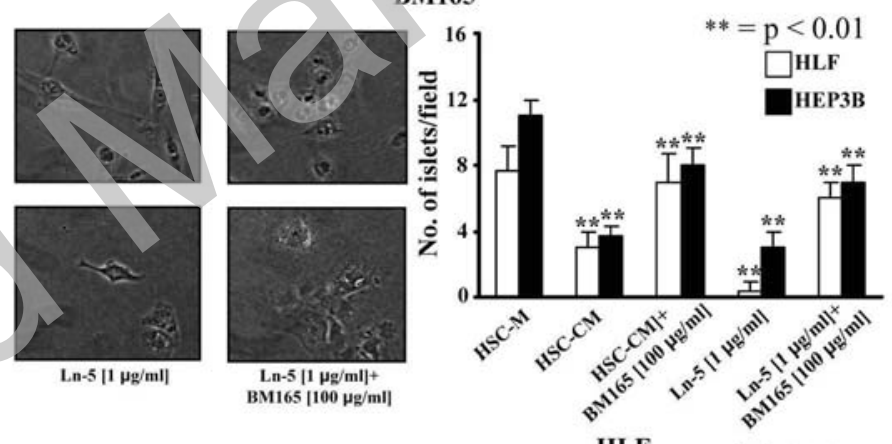

递

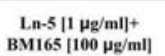

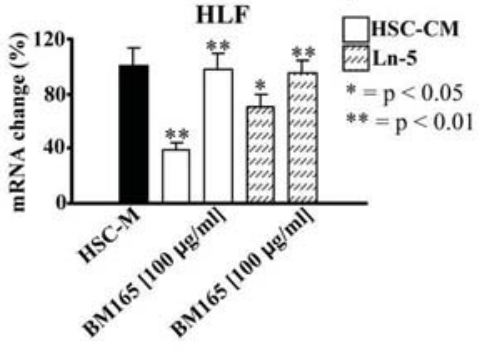


A

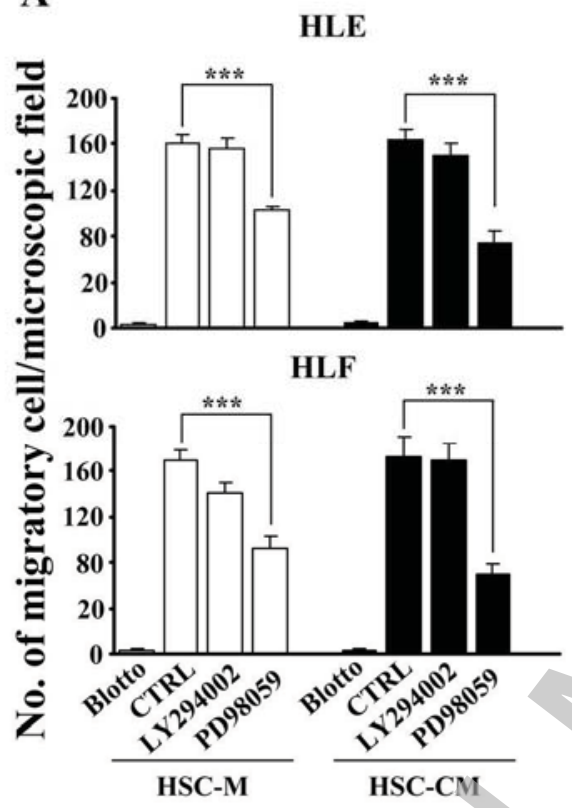

B

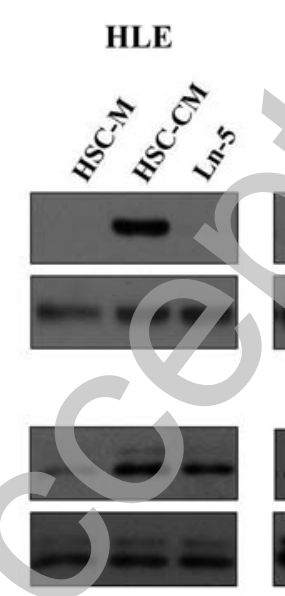

HLF
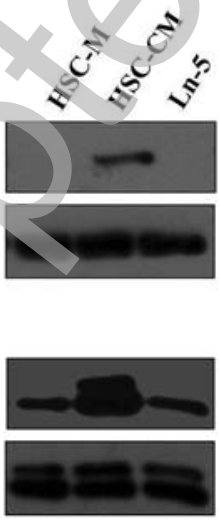

Figure 5
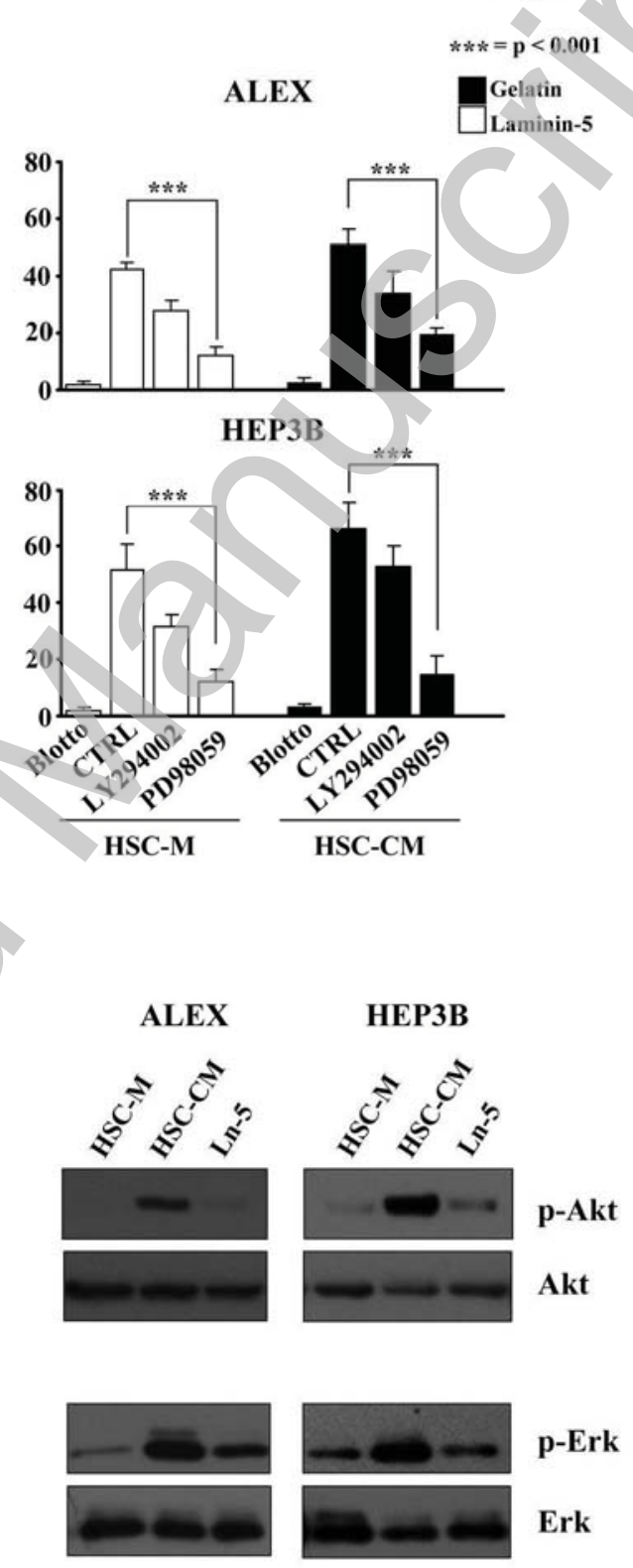


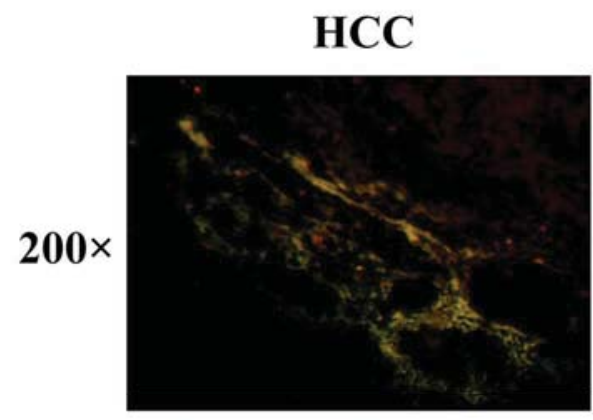

\section{Peritumoral}
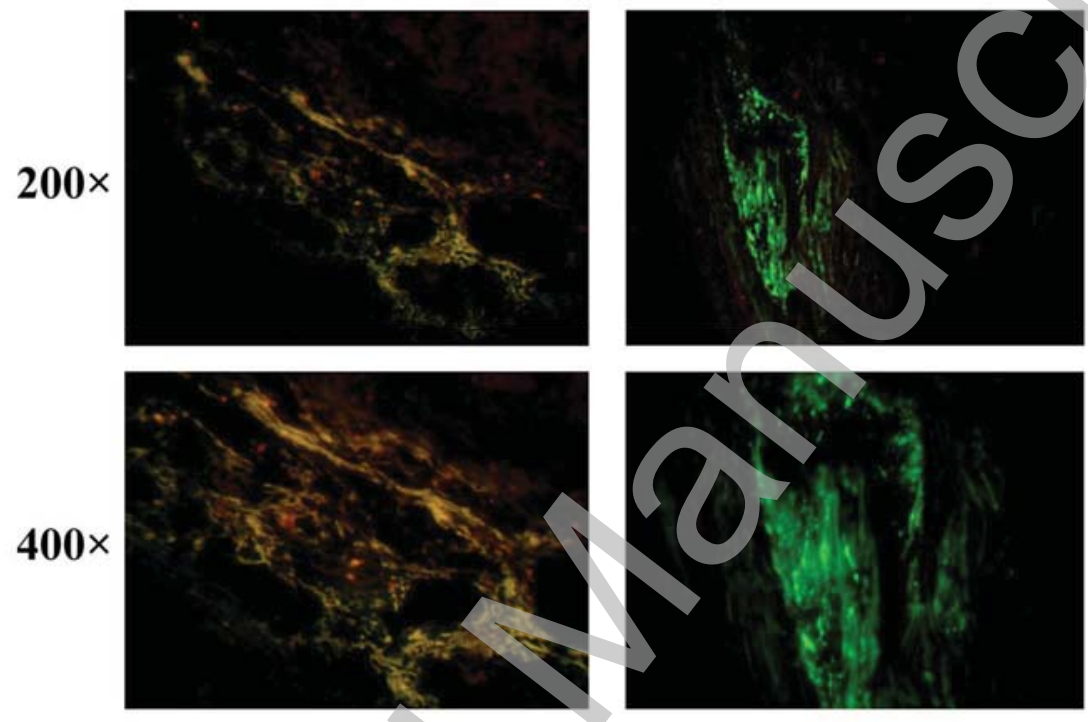

Licenced copy. Copying is not permitted, except with prior permission and as allowed by law. (C) 2011 The Authors Journal compilation (C) 2011 Portland Press Limited 